\title{
Human papillomavirus infection among sexual partners attending a Sexually Transmitted Disease Clinic in Rio de Janeiro, Brazil
}

\author{
L.A. Afonso ${ }^{1,2}$, W.M. Rocha ${ }^{1,3}$, F.N. Carestiato $^{1,2}$, E.A. Dobao ${ }^{1,3}$, L.F. Pesca ${ }^{1}$, \\ M.R.L. Passos ${ }^{4}$ and S.M.B. Cavalcanti ${ }^{1}$ \\ ${ }^{1}$ Laboratório de Diagnóstico Virológico, Departamento de Microbiologia e Parasitologia, Instituto Biomédico, \\ Universidade Federal Fluminense, Niterói, RJ, Brasil \\ ${ }^{2}$ Programa de Pós-Graduação em Ciências Médicas, Universidade Federal Fluminense, Niterói, RJ, Brasil \\ ${ }^{3}$ Programa de Pós-Graduação em Microbiologia e Parasitologia Aplicadas, Universidade Federal Fluminense, Niterói, RJ, Brasil \\ ${ }^{4}$ Setor de Doenças Sexualmente Transmissíveis, Instituto Biomédico, Universidade Federal Fluminense, Niterói, RJ, Brasil
}

\begin{abstract}
Cervical cancer is a major source of illness and death among women worldwide and genital infection with oncogenic human papillomavirus (HPV) its principal cause. There is evidence of the influence of the male factor in the development of cervical neoplasia. Nevertheless, the pathogenic processes of HPV in men are still poorly understood. It has been observed that different HPV types can be found among couples. The objective of the present study was to investigate HPV infections in female patients ( $n=60$ females/group) as well as in their sexual partners and to identify the concordance of HPV genotypes among them. By using the polymerase chain reaction, we detected a 95\% prevalence of HPV DNA in women with cervical intraepithelial neoplasia (CIN) compared to $18.3 \%$ in women with normal cervical epithelium, with a statistically significant difference $(P<0.001)$. The HPV DNA prevalence was $50 \%$ in male partners of women with $\mathrm{CIN}$ and $16.6 \%$ in partners of healthy women. In the control group (healthy women), only 9 couples were simultaneously infected with HPV, and only $22.2 \%$ of them had the same virus type, showing a weak agreement rate (kappa index $=0.2$ ). Finally, we observed that HPV DNA was present in both partners in 30 couples if the women had CIN, and among them, 53.3\% shared the same HPV type, showing moderate agreement, with a kappa index of 0.5 . This finding supports the idea of circulation and recirculation of HPV among couples, perpetuating HPV in the sexually active population, rather than true recurrences of latent infections.
\end{abstract}

Key words: Human papillomavirus; Neoplasia; Couples; Sexual partners; Polymerase chain reaction

\section{Introduction}

Cervical cancer is a major source of illness and death among women worldwide and genital infection with oncogenic human papillomavirus (HPV) its principal cause (1). It is already recognized that most genital HPV infections clear within 1-2 years, but those that persist can progress to precancer and cancer. Several social, demographic and epidemiological factors have been related to cancer establishment, contributing to the risk of HPV infection as well as to the subsequent events such as persistence, integration and transformation (2). In the last decade, several studies have pointed out the significantly increased incidence of genital HPV infections and currently it is estimated that nearly $75 \%$ of sexually active women will be infected at any moment in their lifetime (3).

Although men are assumed to be the main reservoirs of genital HPV infections for women, a limited number of cross-sectional and case-control studies have focused on male infection or have evaluated HPV genotypes in malefemale couples (4-6). The expected transmission rate between partners ranges from $22 \%$ as reported by Hernandez et al. (5) to $60 \%$ according to Schneider et al. (7). Several studies have described a high prevalence of HPV infections in the sexual partners of women with cervical intraepithelial neoplasia (CIN) or condyloma,

Correspondence: S.M.B. Cavalcanti, Laboratório de Diagnóstico Virológico, Departamento de Microbiologia e Parasitologia, Instituto Biomédico, Universidade Federal Fluminense, Rua Prof. Ernani Melo, 101, Sala 321, 24210-130 Niterói, RJ, Brasil. Fax: +55-212629-2433. E-mail: silviacavalcanti@vm.uff.br 
compared to the expected $10 \%$ prevalence in the general population (7). In Brazil, information regarding male HPV infection is primarily derived from studies that have examined husbands of female cervical cancer cases, cross-sectional studies of selected populations (such as individuals treated at sexually transmitted disease clinics) and small prospective studies, which together revealed HPV prevalence rates ranging from 30 to $80 \%$ (8). According to the recommendations of the guidelines on sexually transmitted diseases (STD), every sexual partner of an infected woman must be examined in order to identify, treat, and prevent the continuation of the disease. Giraldo et al. (9) reported that asymptomatic male sexual partners of women with low-grade intraepithelial squamous lesions and infected with high-risk HPV often had abnormal penile tissue compared to HPV(-) male partners. Nevertheless, agreement rates were not studied.

Since there is no adequate animal model of HPV and the disease cannot be studied by in vitro cell cultures, the generation of data from epidemiological studies has been essential to elucidate the biological processes of HPV. The objective of the present study was to determine the prevalence of HPV infection in couples, evaluating male sexual partners of women presenting $\mathrm{CIN}$ as well as in asymptomatic couples, and determining HPV genotype concordance among them.

\section{Material and Methods}

\section{Study design}

This was a cross-sectional study designed to evaluate the presence of HPV infection in couples. Two groups were studied: group I, consisting of female patients presenting $\mathrm{CIN}$ as well as their male sexual partners, and group II, consisting of asymptomatic couples.

\section{Sample}

The study was conducted on 60 women presenting different grades of CIN (25 CIN I, 21 CIN II, and 14 CIN III; group I) and 60 women without CIN (asymptomatic patients; group II) who came to the Setor de Doenças Sexualmente Transmissíveis, Universidade Federal Fluminense for cervical cancer screening (Pap smear), as well as their respective partners. The study was conducted from February 2000 to July 2010. The study was approved by the Ethics Committee of the Universidade Federal Fluminense (protocol \#189/04). All subjects gave written informed consent to participate in the study. All patients were examined and, after applying $5 \%$ acetic acid, scrapings were collected using peniscopy/ colposcopy. Directed biopsies were obtained from areas suggestive of HPV infection and confirmed CIN and normal tissues were selected for this study.

\section{Peniscopy}

Peniscopic images were classified as condilomatous lesions (acuminated, pigmented or non-pigmented warts), lesions suggestive of HPV infection (acetowhite areas, erythematous or macular lesions, papillomas or pearled papules) or normal. Penile scrapes were obtained using a Urotest brush in areas identified by peniscopic images as being of clinical or subclinical significance. All brushes were kept in TE solution (10 mM Tris- $\mathrm{HCl}, \mathrm{pH} 7.5,1 \mathrm{mM}$ EDTA) at $-20^{\circ} \mathrm{C}$ until DNA extraction. Penile smears were classified using clinical/peniscopic terms since cytological and histopathological results were not available for most of the male patients.

\section{Cytology and histopathology}

Cervical smears and biopsies were cytologically and histologically classified as normal epithelium or CIN, according to the 1990 Richart classification at the Cervical Pathology Service of UFF. Samples were collected, kept at $-20^{\circ} \mathrm{C}$ and sent to the Virological Diagnostic Laboratory of the Universidade Federal Fluminense.

\section{HPV detection and typing}

DNA extraction. Samples were incubated for $4 \mathrm{~h}$ at $56^{\circ} \mathrm{C}$ in digestion buffer $(10 \mathrm{mM}$ Tris- $\mathrm{HCl}, \mathrm{pH} 8.3,1 \mathrm{mM}$ EDTA, pH 8.0, 0.5\% Tween 20, and $400 \mu \mathrm{g} / \mathrm{mL}$ proteinase $\mathrm{K}$ ) and subsequently extracted with phenol-chloroform-isoamyl alcohol (25:24:1). The DNA was precipitated with one-tenth volume of $0.3 \mathrm{M}$ sodium acetate and three volumes of ice-cold $100 \%$ ethanol, washed with $70 \%$ ethanol, air-dried, and suspended in $50 \mu \mathrm{L}$ sterile water.

Polymerase chain reaction (PCR) using consensus primers for the detection of HPV. MY09/11 consensus primers, which amplify 450-bp DNA sequences within the L1 region of HPV, were used to detect generic HPV DNA. Amplification was carried out in $50 \mu \mathrm{L}$ of reaction mixture [1X PCR buffer, $200 \mathrm{mM}$ deoxynucleotide triphosphates (dNTPs), $1.5 \mathrm{mM} \mathrm{MgCl}_{2}, 50$ pmol of each primer, $0.25 \mathrm{U}$ Taq polymerase, and $5 \mu \mathrm{L}$ DNA sample] with 35 cycles of amplification. Each cycle included a denaturation step at $94^{\circ} \mathrm{C}$ for $1 \mathrm{~min}$, an annealing step at $55^{\circ} \mathrm{C}$ for $2 \mathrm{~min}$ and a chain elongation step at $72^{\circ} \mathrm{C}$ for 2 min using a DNA Thermal Cycler (Lifetech, USA). The beta-actin primers Ac1 and Ac2 (0.1 pmol each), which amplify a 330-bp region of human DNA, were used as an internal control. Negative controls for background contamination were added to the DNA template. PCR products were analyzed on $1.3 \%$ agarose gel with ethidium bromide staining for visualization of DNA under ultraviolet (UV) light and their molecular weights were determined by comparison with a 100-bp DNA ladder (10).

PCR for HPV genotyping. Typing was done by PCR amplification with primers for the E6 gene DNA sequences of HPV $6,11,16,18,31,33,35,45$, and 58 (10). All 135 samples studied were submitted to this reaction. Amplification was carried out in $50 \mu \mathrm{L}$ of reaction mixture (1X PCR buffer, $200 \mathrm{mM}$ dNTPs, $1.5 \mathrm{mM} \mathrm{MgCl}_{2}$, 
50 pmol of each primer, $0.25 \cup$ Taq polymerase, and $5 \mu \mathrm{L}$ DNA sample) with 35 cycles of amplification. Each cycle included a denaturation step at $94^{\circ} \mathrm{C}$ for $30 \mathrm{~s}$, an annealing step at $55^{\circ} \mathrm{C}$ for $30 \mathrm{~s}$ and a chain elongation step at $72^{\circ} \mathrm{C}$ for 1 min using a DNA Thermal Cycler. Negative controls for background contamination were added to the DNA template. PCR products were analyzed on $1.3 \%$ agarose gel with ethidium bromide staining for visualization of DNA under UV light and their molecular weights were determined by comparison with a 100-bp DNA ladder.

Restriction fragment length polymorphism (RFLP) analysis for HPV genotyping. HPV typing was performed by RFLP analysis following PCR amplification. The 450bp amplicons resulting from the MY09/11 PCR were submitted to digestion with a panel of six restriction endonucleases (BamHI, Ddel, Haelll, Hinfl, Pstl, Rsal) (Invitrogen, Brazil). The pattern of length polymorphism of each sample was analyzed under UV light and compared with RFLP patterns for mucosal virus types, as described by Melgaço et al. (11).

\section{Statistical analysis}

A data bank was generated and analyzed using the Epi Info 2008 statistical software package (Center for Disease Control and Prevention, USA). The differences between biological data were compared by the chi-square test with Mantel-Haenszel correction. Agreement rates were obtained by the Cohen test using the Kappa index. The level of significance was set at 0.05 in all analyses.

\section{Results}

The study population consisted of 120 women with an average age of $27.6 \pm 9.7$ years. Analyses of age groups revealed that group I included older patients $(34.7 \pm 4.1$ years old) while group II (healthy women) included women with an average age of 23.2 years $(S D=5.6)$, with a statistically significant difference between groups $(P<$ $0.01)$. The 120 men studied had an average age of 35.9 \pm 12.3 years. The male partners of group I had an average age of $38.6 \pm 7.3$ years and partners of group II had an average age of $30.2 \pm 11.9$ years, with no significant difference between groups $(P=0.562)$.
The sociodemographic data of female patients (groups I and II) revealed that most of them had monthly incomes of 1-2 minimum salaries (US\$600.00), 52\% had attended only elementary school, $70 \%$ had stable sexual partners, and $72 \%$ had up to 3 lifetime sexual partners. An early onset of sexual activity was observed in $49.3 \%$ of them ( $<17$ years of age). A condom was routinely used by $21.1 \%$ of the couples and $72 \%$ had 2 children or less. Most women (87\%) denied a previous STD.

Total HPV prevalence in women was $56.7 \%(68 / 120)$. HPV DNA was detected in $95 \%$ of group I and in $18.3 \%$ of group II, with a statistically significant difference $(P<0.001)$ (Table 1). In male samples, HPV prevalence was $33.3 \%$ $(40 / 120)$. HPV DNA was detected in $50 \%$ of partners of women from group I and in $16.6 \%$ of partners of women from group II, with a statistically significant difference between groups $(P<0.001$; Table 2$)$.

High-risk viruses prevailed in both groups I (70\%, 42) $60)$ and II $(13.3 \%, 8 / 60)$, with statistically significant differences (70 vs $13.3 \%, \mathrm{P}<0.0001$; Table 1). For the male partners, the frequency of oncogenic HPV type was $30 \%(18 / 60)$ for group I partners and $11.6 \%$ (7/60) for group II partners (Table 2), with a statistically significant difference $(P<0.03)$. In group I, HPV typing revealed a high prevalence of HPV 16 (52.4\%), followed by HPV 45 (16.7\%) and HPV 18 (14.3\%). For group II, HPV 16 was also the most prevalent (45.5\%), followed by HPV 6 and HPV 18 (18.2\%).

The male lesions found by peniscopy ( $n=22$ ) were biopsied and peniscopic diagnosis was confirmed by histopathological analysis. All of them affected partners of women with CIN (group I). In this male group, only 4 had evident clinical lesions, characterized as acuminated condyloma. The other 18 were subclinical carriers of HPV DNA, presenting acetowhite lesions $(n=14)$ or pearl papules $(n=4)$. PCR revealed that, except for 6 acetowhite lesions, all of them (16/22, 72.7\%) presented HPV infection (Table 2). Nearly all partners (59/60) of women from group II were also normal at peniscopy, as well as in cytology scrapes but 9 of them had HPV DNA detected in penile scrapes (15\%).

In group I, both partners of 30 couples had HPV DNA. Among them, 16 couples shared the same HPV type $(53.3 \%)$, with a moderate agreement rate and a kappa

Table 1. Frequency of HPV DNA detection by PCR in female patients from groups I (CIN) and II (asymptomatic) according to histological diagnosis.

\begin{tabular}{|c|c|c|c|c|}
\hline \multirow{2}{*}{$\begin{array}{l}\text { Diagnosis at } \\
\text { histopathology }\end{array}$} & \multicolumn{4}{|c|}{ Infection by HPV in female patients } \\
\hline & High-risk HPV & Low-risk HPV & Multiple HPV types & Total prevalence \\
\hline Group I & $34 / 60(56.7 \%)$ & $11 / 60(18.3 \%)$ & $12 / 60(20 \%)$ & $57 / 60(95 \%)$ \\
\hline Group II & $8 / 60(13.3 \%)$ & $3 / 60(5 \%)$ & $-(0 \%)$ & $11 / 60(18.3 \%)$ \\
\hline
\end{tabular}

Data are reported as number of patients with percent in parentheses. HPV = human papillomavirus; CIN = cervical intraepithelial neoplasia. 
Table 2. Frequency of HPV DNA detection by PCR in male partners of both healthy women and women with CIN according to peniscopy.

\begin{tabular}{|c|c|c|c|c|}
\hline \multirow[t]{2}{*}{ Diagnosis at peniscopy } & \multicolumn{4}{|c|}{ Infection by HPV in male partners } \\
\hline & High-risk HPV & Low-risk HPV & Multiple infections & Prevalence of HPV \\
\hline $\begin{array}{l}\text { Partners of group I (CIN) showing } \\
\text { altered peniscopy }\end{array}$ & $6(27.3 \%)$ & $7(31.8 \%)$ & $3(13.6 \%)$ & $16 / 22(72.7 \%)$ \\
\hline $\begin{array}{l}\text { Partners of group I (CIN) with } \\
\text { normal peniscopy }\end{array}$ & $9(23.7 \%)$ & $5(13.2 \%)$ & - & $14 / 38(36.8 \%)$ \\
\hline Total partners of group I & $15 / 60(25 \%)$ & $12 / 60(20 \%)$ & $3 / 60(5 \%)$ & $30 / 60(50 \%)$ \\
\hline $\begin{array}{l}\text { Partners of group II } \\
\text { (asymptomatic women) }\end{array}$ & $6 / 60(10 \%)$ & $3 / 60(5 \%)$ & $1 / 60(1.6 \%)$ & $10 / 60(16.6 \%)$ \\
\hline
\end{tabular}

Data are reported as number of patients with percent in parentheses. HPV = human papillomavirus; CIN = cervical intraepithelial neoplasia.

index of 0.5. In group II, only 9 couples were simultaneously infected with HPV, and only 2 of them had the same virus $(22.2 \%)$.

\section{Discussion}

Persistent human papillomavirus infection causes almost all cervical cancers and many vulvar, vaginal, penile, anal, and oropharyngeal cancers. Although the incidence of these cancers is influenced by sexual behaviors, recent data of the HIM (human papillomavirus infection in men) study strongly suggested that the natural history of HPV differs between men and women (12). It has been shown that there is a pattern of high infection and low disease rates in men, contrasting with low infection and high disease rates in women. In that study, the investigators also pointed out that Brazil has the highest incidence of both oncogenic and non-oncogenic HPV infection in the male population (12). Corroborating these data, we found that $50 \%$ of sexual partners of women with CIN (group I) harbored HPV in lesions and that these were predominantly subclinical (Table 2). Other studies showed similar rates of HPV infection $(13,14)$. As discussed by Giraldo et al. (9), the role of the sexual partners of women with HPVassociated lesions has been widely discussed; however, there is no established agreement. Although the diagnosis and treatment of acetowhite lesions in men do not seem to alter or improve the progress of the squamous intraepithelial lesions in their female partners, these acetowhite lesions on male genitalia, which are in fact squamous intraepithelial alterations, should not be left untreated, due to the risk of their further development. Since the role of HPV infection and circulation in the population is not clear, systematic studies are necessary in order to avoid a vicious cycle of infection-treatment-reinfection or even progression of HPV lesions to cancer.

Regarding group II, asymptomatic women had an HPV prevalence of $18.3 \%$, and their partners presented infection in $16.6 \%$ of the samples, with no statistically significant differences $(P=0.9)$, similar to the rates described in other studies from Rio de Janeiro, Brazil (10).

In our study, high-risk HPV prevailed in both groups and II, accounting for 70 and $13.3 \%$ of infections, respectively. HPV 16 was the most prevalent type, representing $52.4 \%(22 / 42)$ of the oncogenic types studied. Oncogenic HPV 45 also showed a high prevalence rate (16.7\%), followed by HPV 18 (14.3\%; Table $3)$. This may have been due to a biological replacement in ecological niches occurring either naturally or in response to selective pressure resulting from vaccination programs. In Brazil, HPV vaccines have been licensed since 2006 but have not been extensively used due to their high cost; hence, the possible effects on the epidemiology of HPV infection are not yet known. In addition, we studied a lowincome population to whom HPV vaccines would not be expected to be available.

Nevertheless, it is interesting to note that HPV 45 belongs to the same phylogenetic clade as HPV 18, the most oncogenic and aggressive HPV type related to human cancer that is associated with a poor prognosis in terms of response to treatment, as well as overall survival (15). Due to the similar genetic profile, we suggest that HPV 45 might also be associated with a poor prognosis, meriting further follow-up studies. de Sanjose et al. (1) showed that HPV 45 is rarely seen in precursor lesions, a fact that may support the idea of an early poor outcome, even in screened women.

Low-risk types were detected in $15 \%$ of group I and $5 \%$ of group II subjects (Table 1). Among the male partners of group I we found similar prevalence rates for high- and low-risk viruses (30 and 20\%, respectively), while for male partners of group II women the rates were $11.6 \%$ for high risk and $5 \%$ for low risk, with no significant difference $(P>0.1)$.

Rombaldi et al. (13) detected a prevalence of types 6 and 11 in couples, while Paesi et al. (16), in a prospective study of couples, among which women presented CIN III, detected a prevalence of HPV types 16 and 18. Our results are similar to those reported by Paesi et al. (16), showing a high prevalence of HPV 16. 
Table 3. Frequency of HPV genotypes detected by PCR and RFLP in samples of female patients from groups I (CIN) and II (asymptomatic).

\begin{tabular}{lccccccc}
\hline HPV genotypes & HPV 6 & HPV 11 & HPV 16 & HPV 18 & HPV 45 & Other HPV & Total \\
\hline Group I & 6 & 3 & 22 & 6 & 7 & $7^{*}$ & 60 \\
Group II & 2 & 1 & 5 & 2 & - & $1^{\text {** }}$ & 60 \\
\hline
\end{tabular}

* Other HPV revealed by PCR/RFLP: HPV 33 (2), HPV 35 (1), HPV 56 (1), HPV 58 (2), HPV 73 (1). ** Low-risk HPV in asymptomatic women: HPV 54 (1). HPV = human papillomavirus; $\mathrm{CIN}=$ cervical intraepithelial neoplasia.

Diverse rates of concordance in HPV types have been described in various studies on couples, ranging from 60 to $10 \%$ : Widdice et al. (17) studied heterosexual couples infected with HPV and detected concordant HPV types in more than $60 \%$ of cases, while Castellsagué et al. (18) found $32 \%$ of agreement and suggested that this low rate was due to the different levels of biological activity of the male and female genital tract as well as to differences in local immunity and organization of the genital epithelia of each sex. Physical and immunological protection against pathogenic processes may account for the establishment of different HPV genotypes at specific genital sites. The degree of keratin expression, the number of epithelial layers within each stratum as well as colonization by bacterial flora may determine different patterns of viral infection (19). Rosenblatt et al. (6) found only $13 \%$ of agreement, and proposed a complete different panel, whereby reincidence of lesions in CIN women might not be associated with reinfection from sexual partners but rather with a true recurrence of a latent infection. Nevertheless, there is no experimental model of HPV infection insuring the occurrence of true latency, and proposals are mainly theoretical, based on other DNA viruses that infect the genital tract, such as herpes simplex virus. Hence, latency remains a possible outcome of HPV infection but needs to be elucidated. Gravitt (20) has already mentioned that currently there are no tools to conclusively differentiate latency, persistence and transition status of infection and reinfection.

\section{References}

1. de Sanjose S, Quint WG, Alemany L, Geraets DT, Klaustermeier JE, Lloveras B, et al. Human papillomavirus genotype attribution in invasive cervical cancer: a retrospective cross-sectional worldwide study. Lancet Oncol 2010; 11: 1048-1056, doi: 10.1016/S1470-2045(10)70230-8.

2. Xiaocheng W. Human papillomavirus associated cancers 2004-2008. Morbidity and mortality weekly report. CDC Weekly Report 2012; 258-261.

3. Munoz N, Kjaer SK, Sigurdsson K, Iversen OE, HernandezAvila M, Wheeler CM, et al. Impact of human papillomavirus (HPV)-6/11/16/18 vaccine on all HPV-associated genital diseases in young women. $J$ Natl Cancer Inst 2010; 102: 325-339, doi: 10.1093/jnci/djp534.

4. Baken LA, Koutsky LA, Kuypers J, Kosorok MR, Lee SK,
Recently, the Brazilian government instituted a working group to discuss the inclusion of HPV prophylactic vaccines in the Brazilian Immunization Program (PNI). Hence, ongoing surveillance of HPV-associated lesions using high-quality population-based registry and a consistent methodology is needed to monitor the impact of HPV vaccines and cervical cancer screening practices influencing transmission and clearance rates associated with disease development (2). Although the HIM study demonstrated that the prevalence of viral types composing the HPV vaccine is low, our results showed that most infections were caused by low-risk HPV 6 and 11 and high-risk HPV 16 and 18 (data not shown), thus indicating a relevant impact on vaccine design.

In the present study, we observed a significantly higher rate of infection among partners of women with $\mathrm{CIN}$, with $50 \%$ of agreement in the genotypes detected, indicating the circulation of these viruses among the couples, assuring HPV transmission and maintenance in the sexually active population. Finally, the molecular detection of HPV proved to be a good tool to identify HPV infection, revealing that, half of the time, HPV genotypes can elucidate the perpetuation of the infectious processes among couples.

\section{Acknowledgments}

Research supported by CAPES, FAPERJ (APQ1, \#E26/160.511/2010) and PROAP/UFF 2011.

Kiviat NB, et al. Genital human papillomavirus infection among male and female sex partners: prevalence and typespecific concordance. J Infect Dis 1995; 171: 429-432, doi: 10.1093/infdis/171.2.429.

5. Hernandez BY, Wilkens LR, Zhu X, Thompson P, McDuffie $\mathrm{K}$, Shvetsov YB, et al. Transmission of human papillomavirus in heterosexual couples. Emerg Infect Dis 2008; 14: 888-894.

6. Rosenblatt C, Lucon AM, Pereyra EA, Pinotti JA, Arap S, Ruiz CA. HPV prevalence among partners of women with cervical intraepithelial neoplasia. Int J Gynaecol Obstet 2004; 84: 156-161, doi: 10.1016/j.ijgo.2003.08.008.

7. Schneider A, Kirchmayr R, De Villiers EM, Gissmann L. Subclinical human papillomavirus infections in male sexual 
partners of female carriers. J Urol 1988; 140: 1431-1434.

8. WHO/ICO - World Health Organization/Institut Català d'Oncologia. Information Centre on HPV and Cervical Cancer. Human papillomavirus and related cancers in Brazil. Summary report. http//:www.who.int/hpvcentre.

9. Giraldo PC, Eleuterio J Jr, Cavalcante DI, Gonçalves AK, Romão JA, Eleuterio RM. The role of high-risk HPV-DNA testing in the male sexual partners of women with HPVinduced lesions. Eur J Obstet Gynecol Reprod Biol 2008; 137: 88-91, doi: 10.1016/j.ejogrb.2006.12.026.

10. Silva KC, Rosa ML, Moyse N, Afonso LA, Oliveira LH, Cavalcanti SM. Risk factors associated with human papillomavirus infection in two populations from Rio de Janeiro, Brazil. Mem Inst Oswaldo Cruz 2009; 104: 885891, doi: 10.1590/S0074-02762009000600011.

11. Melgaço FG, Rosa ML, Augusto EF, Haimuri JG, Jacintho C, Santos LS, et al. Human papillomavirus genotypes distribution in cervical samples from women living with human immunodeficiency virus. Arch Gynecol Obstet 2011; 283: 809-817, doi: 10.1007/s00404-010-1443-z.

12. Giuliano AR, Lazcano-Ponce E, Villa LL, Flores $R$, Salmeron J, Lee $\mathrm{JH}$, et al. The human papillomavirus infection in men study: human papillomavirus prevalence and type distribution among men residing in Brazil, Mexico, and the United States. Cancer Epidemiol Biomarkers Prev 2008; 17: 2036-2043, doi: 10.1158/1055-9965.EPI-08-0151.

13. Rombaldi RL, Serafini EP, Villa LL, Vanni AC, Barea F, Frassini $R$, et al. Infection with human papillomaviruses of sexual partners of women having cervical intraepithelial neoplasia. Braz J Med Biol Res 2006; 39: 177-187, doi: 10.1590/S0100-879X2006000200003

14. Bleeker MC, Snijders PF, Voorhorst FJ, Meijer CJ. Flat penile lesions: the infectious "invisible" link in the transmission of human papillomavirus. Int J Cancer 2006; 119: 25052512, doi: 10.1002/ijc.22209.

15. Chen Z, DeSalle R, Schiffman M, Herrero R, Burk RD. Evolutionary dynamics of variant genomes of human papillomavirus types 18, 45, and 97. J Virol 2009; 83 1443-1455, doi: 10.1128/JVI.02068-08.

16. Paesi SO, Serafini EP, Madi SRC. Determinação e tipagem do papillomavirus humano (HPV) em amostras de população feminina atendida no Ambulatório de Patologia Cervical do Ambulatório Central da Universidade de Caxias do Sul. Rev Ciênc Méd Univ Caxias do Sul 2003; 2: 16-22.

17. Widdice LE, Breland DJ, Jonte J, Farhat S, Ma Y, Leonard $\mathrm{AC}$, et al. Human papillomavirus concordance in heterosexual couples. J Adolesc Health 2010; 47: 151-159, doi: 10.1016/j.jadohealth.2010.01.006.

18. Castellsagué X, Ghaffari A, Daniel RW, Bosch FX, Munoz $\mathrm{N}$, Shah KV. Prevalence of penile human papillomavirus DNA in husbands of women with and without cervical neoplasia: a study in Spain and Colombia. J Infect Dis 1997; 176: 353-361, doi: 10.1086/514052.

19. zur Hausen H. Papillomaviruses and cancer: from basic studies to clinical application. Nat Rev Cancer 2002; 2: 342350, doi: $10.1038 /$ nrc798.

20. Gravitt PE. The known unknowns of HPV natural history. $J$ Clin Invest 2011; 121: 4593-4599, doi: 10.1172/JCI57149. 